\title{
Obesity in adolescent females is cause of nutritional imbalance
}

\author{
Shwetma Mishra \\ SRO, Dept. of ENT, All India Institute of Medical Sciences (AIIMS), New Delhi, India \\ *Corresponding Author: Shwetma Mishra \\ Email: drsmicmr@gmail.com
}

\begin{abstract}
Anemia is the most common disorder of the blood and it is very typical to identify anemia. Many biotechnological tools are developed regularly for identification of anemia e.g. Analyzers' for CBC counting, Neubauer chamber for cell counting, Microscopic findings of Bone marrow examination etc. The tools are developed accordingly where there is less errors in assessing and also keeping in mind that less sample may be drawn from sufferer. The objectives of the study were to identify Anemia in various age groups females carried out with the following.

Materials and Methods: The blood can be collected (without clots) by veripuncture in the EDTA tube (dipotassium salt) for the test performing are Complete Blood Count (CBC) including Erythrocyte Sedimentation Rate (ESR, method: wintrobe) by using automatic analyzer. Few samples was also examined by POC microscope for further evaluations or analysis. The collected blood samples of 1000 females includes with their symptomatic analysis of present and past history via questionnaire. Then findings are evaluated with sign and symptoms of sick persons, with their family history, clinical history and physical examinations (according to available data) for confirming Anemia. Results were categorized at different categories groups.

Results: From the hematological analysis done by using automated analyzer and PDM device of one thousand samples, 57\% samples are found as anemic. When their comparative analysis was performed with their weight it was found that about $34.9 \%$ females are overweight and affected with disease condition. When categorized type it was found that $29.2 \%$ students affected with mild anemia, $4.8 \%$ are by moderate anemia and $0.8 \%$ were with severe anemia. The maximum anemia cases of students living in PG or hostiles.

Conclusion: After performing the hematological analysis it is found that $57 \%$ of sample indicating anemia. Day scholar $68.6 \%$ and hostiles $81.6 \%$ had prone to anemia. It was also seen $1.6 \%$ females with severe anemia. Some non anemic about $10 \%$ samples are also shows anemic condition with no symptoms of anemia. They are either suffered by chronic illness or infected by blood parasite. PDM device indicated around 5\% of cases are with infectious disease cases like Tuberculosis or any other previous illness. The food habit of hostile was worse than those of day scholars. Their food may not contain nutritional content and their food habits are only sustaining their hunger but not supportive with health as much as they required. Based upon a relatively small body of evidence, there appears to be a strong and clinically significant association between anemia and different life threatening diseases like cardiovascular morbidity and mortality in MDS. While further research is needed, clinicians should seek to actively manage hemoglobin levels in all chronic disease patients before the point of transfusion dependency is reached.
\end{abstract}

Keywords: CBC, Blood parasite, Anemia, Mortality, Morbidity, Hemoglobin, Transfusion.

\section{Introduction}

Food which is a basic need of our body. If we can not take a proper intake of protein rich food we suffers from lots of illness in our later lives. As we developed so many tools and techniques for diagnosis and treatment of so many diseases i.e. infectious or non-infectious one, but we cannot focus on the basic things like food habit of our daily course of work. Nutritional deficiency in college going females especially when they lived in the hostel, PG or accommodating in rental houses.

Food habits are responsible factor for obesity in adolescent females now days.

A very natural need for all living being is food for survival. But in humen being, the selection of food plays a very important role in affecting one's health.

Every day, several times a day man makes food choices may benefit or harm your health a little but when these choices are repeated over years and decades the reward or consequences become major, as such close attention to good eating habits now can bring health benefits later. Conversely carelessness about food choices from youth onwards can bring about too many chronic diseases, prevalent in later life like cancer, heart diseases, diabetes etc.
Even realized that food habit affect the health. People choose food for other reasons also, like taste, tradition, associations. This is the major issue now days so finding its cause and imbalances will procure from many disease risk in future.

\section{Materials and Methods \\ Study cross sectional \\ Sample Size: 1000}

Anticoagulant of Choice: EDTA- Complete Blood Counts (CBCs), Erythrocyte Sedimentation Rates (ESRs)

\section{Standard Normal Ranges of Blood Cells}

PDM (Portable Digital Microscope)

\section{Collection of Blood Sample}

The blood can be collected by veripuncture. The collected blood samples of 1000 sick persons according to their age groups are taken for the study of anemia.

\section{Preparing Blood Smears \\ ( $\mathrm{Zn}$ staining is done) \\ Using venous blood, blood smears should be prepared as soon as possible after collection (delay can result in changes in parasite morphology and staining characteristics). The samples was putted in automated}


analyzer for the study. Few samples was also examined by microscope for further evaluations or analysis. Results was categorized by different age groups.

\begin{tabular}{|c|c|}
\hline WBC & $3000-7000 * 10^{9}$ \\
\hline RBC & $5.0+/-0.510^{9} / 1$ \\
\hline HGB & $11.0-18.0 \mathrm{gm} / 1$ \\
\hline PLT & $150-400 * 10^{9} / 1$ \\
\hline Neutrophils & $40-80 \%$ \\
\hline Lymphocytes & $20-40 \%$ \\
\hline Monocytes & $2-10 \%$ \\
\hline Eosinophils & $1-6 \%$ \\
\hline Basophils & $<1-2 \%$ \\
\hline ESR & $0-10 \mathrm{~mm} / 1^{\text {st }}$ hour(male) \\
& $0-20 \mathrm{~mm} / 1^{\text {st }}$ hour(female $)$ \\
\hline
\end{tabular}

\section{Analysis of Anemic Samples}

A study conducted of 1000 populations of female college going students. From the hematological analysis done by using automated analyzer of one thousand samples, $57 \%$ samples are found as anemic. On further analysis with Portable digital microscope of anemic and $10 \%$ of nonanemic cases were also reported as anemic.

It was found that about $34.9 \%$ females are overweight and affected with disease condition. When categorized type it was found that $29.2 \%$ students affected with mild anemia, $4.8 \%$ are by moderate anemia and $0.8 \%$ were with severe anemia. The maximum anemia cases of students living in PG or hostiles. This indicates their eating habits affect them more.

After performing the hematological analysis with PDM device analysis it is found that $10 \%$ of sample indicating anemia which have only symptomatic disorder. They are either suffered by chronic illness or infected by blood parasite. PDM device indicated around $5 \%$ of cases are with infectious disease cases like Tuberculosis or any other previous illness. The random selection of ten samples indicates with low hemoglobin count and with only symptomatic disorder which signifies that the oxygen carrying capacity of blood is reduced, which can be due to defective erythropoisis or high erythrocyte destruction rate (hemolysis or jaundice like disease). They are either suffered by chronic illness or infected by blood parasite/ Infections of microbes like Tuberculosis bacilli. It is also found out that traumatic disorder is also responsible for the cause of anemia. Some samples shows that may be hereditary or acquired cases.

\section{Future Prospects}

The study of anemia and other bacterial diseases deals with the treatment of blood related disorders \& tumors that are present in the human body. The study has vital plans that will in the future shaping the society's overall health.

Therefore the study of anemia itself has various impacts that are vitally considered as positive for the society. The morbidity rate of MDS patients was also because of this disorder and there are various researches going in the field for early diagnosis and treatment that will help the doctors to treat this disease with more cautions and with more knowledge as well as understanding and therefore can tackle the disease with more effectiveness and come up with better results.

Thus the field of anemia indeed plays a significant role in the development of the society.

\section{Acknowledgments}

This work is carried out by me at Department of Public Health, SHUATS, Allahabad. I feel privilege to have completed my research work with the able and experienced guidance of Dr. Sanjay Soni (ALLEN group, Kota, Rajasthan). I owe my deepest gratitude to Dr. Sanjay Soni as co-Investigator for introducing me PDM for diagnosis of Anemia and other bacterial diseases and without his continuous optimism concerning this work, enthusiasm, encouragement and support this study would hardly have been completed. I am also thanks to Prof. (Dr.) S. B. lal (Director of Research, Pro VC, SHUATS, Allahabad) and my co-workers who had given me their support. Without team work it is very difficult to make this research report. I am also thankful to research group labs and colleges, Where I profound my Study and also for their cooperation.

\section{Conflict of Interest: None.}

\section{References}

1. MedicineNet.com --> Definition of Anemia Last Editorial Review: 12/9/2000 8:31:00 AM.

2. Merriam-webster dictionary --> anemia Retrieved on May 25, 2009.

3. eMedicine - Anemia, Chronic: Article by Fredrick M Abrahamian, DO, FACEP.

4. The Franklin Institute Inc. Blood - The Human Heart. http://www.fi.edu/learn/heart/blood/blood.ht ml. Retrieved 19 March 2009.

5. Hébert PC, Wells G, Blajchman MA. A multicenter, randomized, controlled clinical trial of transfusion requirements in critical care. Transfusion Requirements in Critical Care Investigators, Canadian Critical Care Trials Group. N Engl J Med 1999;340(6):409-17.

6. Bush RL, Pevec WC, Holcroft JW. A prospective, randomized trial limiting perioperative red blood cell transfusions in vascular patients. Am J Surg 1997;174(2):143-8.

7. Bracey AW, Radovancevic R, Riggs SA. Lowering the haemoglobin threshold for transfusion in coronary artery bypass procedures: effect on patient outcome. Transfus 1999;39(10):1070-7.

8. McIntyre LA, Fergusson DA, Hutchison JS. Effect of a liberal versus restrictive transfusion strategy on mortality in patients with moderate to severe head injury. Neurocritical Care 2006;5(1):4-9.

9. Corwin HL, Gettinger A, Pearl RG. The CRIT Study: Anemia and blood transfusion in the critically ill - current clinical practice in the United States. Crit Care Med 2004;32(1):39-52.

10. Vincent JL, Baron JF, Reinhart K. Anemia and blood transfusion in critically ill patients. JAMA 2002;288(12):1499507.

11. Undersea and Hyperbaric Medical Society. Exceptional Blood Loss - Anemia. http://www.uhms.org/ResourceLib rary/Indications/Exceptional Blood Loss Ane mia/tabid/277/Default.aspx. Retrieved 2008-05-19. 
12. Hart GB, Lennon PA, Strauss MB. Hyperbaric oxygen in exceptional acute blood-loss anemia. J Hyperbaric Med 1987;2(4):205-10.

13. Van Meter KW. A systematic review of the application of hyperbaric oxygen in the treatment of severe anemia: an evidence-based approach. Undersea Hyperb Med 2005;32(1):61-83.

14. http://www.nhlbi.nih.gov/health/dci/Disease s/anemia/anemia_diagnosis.html

15. Ambaglio I, Travaglino E, Della Porta MG, Pascutto C, Ubezio M, Invernizzi R, Malcovati L, Cazzola M. The impact of the degree of anemia on survival of patients with myelodysplastic syndrome. A basis for prognostic assessment and clinical decision making. Haematologica 2010;95(2):124.

How to cite this article: Mishra S. Obesity in adolescent females is cause of nutritional imbalance. $J$ Community Health Manag 2019;6(1):30-32. 